\title{
A look at the impact of ICT on the informational power relationship between corporations and consumers
}

\author{
Christopher Lueg \\ Department of Information Systems, University of Technology Sydney, PO Box 123, Broadway \\ NSW 2007, Australia \\ lueg@it.uts.edu.au
}

Key words: Agent of Change, Cyber Surveillance, Electronic Communication, Globalisation, Internet

\begin{abstract}
Prior to the proliferation of access to global computer networks, people were mainly passive consumers of corporate information disseminated via centrally owned and operated media, such as broadcasting, television, and newspapers. Branding is a marketing technique that has largely benefited from this unidirectional information flow to consumers from corporate information sources. Branding aims at positioning products in the consumer's mind by associating a product, a service or a corporation with a unique name, logo, or selling theme, such as belonging to a certain group because of consuming a particular product. ICT, such as the Internet and the World Wide Web in particular, have enabled ordinary people to disseminate information to a large audience as well as to retrieve information from a variety of information sources beyond corporate spheres of influence. This means that ICT directly impact the informational power relationship between corporations and consumers. This paper examines the current role of information and communication technologies in this context, and speculates on future roles of ICT.
\end{abstract}

The original version of this chapter was revised: The copyright line was incorrect. This has been corrected. The Erratum to this chapter is available at DOI: 10.1007/978-0-387-35663-1_34 


\section{INTRODUCTION}

The importance of ICT has increased significantly over the past few years. The daily lives of people are increasingly affected by information technology and network-related services, and the rise of the network society is regularly discussed. Compared to the prevailing term "information society", "network society" pays more attention to the fact that processing information has been important for decades while networks have only recently begun to re-define notions of time and (physical) location. Eriksson (1999) argues that we are witnessing the early phases of a societal transformation that will be as dramatic as the first two industrial revolutions that are commonly associated with steam and railways, and electricity and the automobile, respectively. In analogy, networks have effects similar to those of railways whereas non-networked (but nevertheless informationprocessing) computers have had effects more similar to those of stationary steam engines.

Global computer networks, such as the Internet, have revolutionised the way information is disseminated and accessed. Prior to the advent of the Internet and the World Wide Web, in particular, people were more or less passive consumers of information disseminated via traditional media, such as broadcasting, television and newspapers. The tools of information flow required large investments and it was easy to identify those controlling these media (Spencer 1997). Information provided by these media along with corporate press releases and advertisements were the most significant ways (and often the only ones) people could use to inform themselves about corporations, their products and the quality of the products. In contrast, the Internet has enabled ordinary people to disseminate information to a large audience and to retrieve information provided by a variety of sources. These range from corporate information to sources provided by competitors to those operated by disgruntled consumers or anti-corporate movements.

This paper explores the role of ICT through the example of branding. This marketing technique has largely benefited from the uni-directional information flow to consumers from corporate information sources. Providing access to a variety of independent information sources means ICT directly impact the informational power relationship between corporations and consumers.

\section{THE FIGHT FOR THE CONSUMER'S MIND}

Branding denotes "the act of differentiating a product or service or corporation with a unique name, logo, positioning, selling theme, etc." 
(Upshaw quoted in Kania 2001). Brands represent promises about what consumers can expect from a product, a service or a company. A different perspective on branding is provided by Downes (1999) describing it as:

"Advertising today looks for stronger hooks, and it finds them in association and self-identification. The concept is especially simple: find (or define) a person's conception of self which is pleasing. Mould that conception such that the use of a product or service is essential to that conception. Imprint the idea that in order to be yourself, you need to purchase such-and-such a brand."

Downes outlines how this is used to sell products:

"The product, no longer able to offer satisfaction on its own ground ("a potato chip is a chip is a chip"), instead offers the consumer a chance to be part of a certain 'crowd' or 'scene'."

Memes play a central role in the fight for the consumer's mind. A meme is $\mathrm{a}$ :

"contagious idea that replicates like a virus, passed on from mind to mind. Memes function the same way genes and viruses do, propagating through communication networks and face-to-face contact between people." (Bennahum quoted in Downes 1999).

Others see corporate ideas and slogans as similar to memes that can be used to "influence certain stakeholders' set of beliefs in such a way that they internalise a positive image of the company". (Porak et al 2000). Media play a double-edged role. They can be used to propagate "corporate memes" and for meme-based "counterattacks" - for example as a tool to attack the information flow from corporate media:

"The methodology of counterattack involves inserting counter-memes into the media mainstream. It is the idea of the meme conceived as virus taken to its logical extreme." (Downes 1999).

The power of meme-like activities was demonstrated recently when an MIT student managed to associate the terms "Nike" and "sweatshop". His email exchange with Nike when trying to order running shoes customised with the word "sweatshop" (Peretti 2001) was widely circulated on the Internet and was reported in a range of more traditional media (MediaGuardian 2001). The power of memes is important as is seems that 
corporate branding strategies do not only provide certain benefits, but also may introduce certain vulnerabilities. Klein (2000) argues that brand images are the corporate Achilles' heel:

"multinationals like Nike, Microsoft and Starbucks have sought to become the chief communicators of all that is good and cherished in our culture: art, sports, community, connection, equality."

Klein argues that the focus on brands has made these corporations the more vulnerable to attacks the more successful they are:

"if brands are indeed intimately entangled with our culture and our identities, when they do wrong their crimes are dismissed as merely the misdemeanours of another corporation trying to make a buck. Instead, many of the people who inhabit their branded worlds feel complicit in their wrong, both guilty and connected. But this connection is a volatile one: it is not the old-style loyalty between lifelong employee and corporate boss; rather, it is a connection more akin to the relationship of fan and celebrity: emotionally intense but shallow enough to turn on a dime."

The Economist (2001) argues that:

"the more companies promote the value of their brands, the more they will need to seem ethically robust and environmentally pure. .... The fact remains that brands give [protesters] far more power over companies than they would have otherwise."

\section{BRANDING AND ICT'S DOUBLE-EDGED ROLE}

From a corporate perspective, ICT and the World Wide Web in particular have enabled novel ways to address customers and shareholders:

"traditionally, branding messages have been unidirectional, delivered to customers via radio, TV, magazines, and other media. In contrast, the Web allows two-way communication - a dialogue in which buyer and seller learn more about one another." (Kania 2001)

Aaker and Joachimsthaler (2000) argue that "to understand the Web, an experience-based model such as a theme park or a retail store is a better metaphor than passively received advertising." and that interaction with other people on a corporate Web site has the potential to create "a 
meaningful social experience involving the brand". According to Kania "the Web has erased the limits defining how customers can experience brands".

Anti-corporate movements see a different role for ICT:

"with increased public access to the Internet in the late 80 s and early 90 s, meme hacking was given a new life. While their access to mainstream media was still limited, activists could now communicate with each other in rapid, free and uncensored messages. Moreover, the Internet and especially the World Wide Web gave them a means of reaching directly into the mainstream consciousness, bypassing the media altogether."

Klein (2000) quotes Peter Verhille of Entente International outlining:

"one of the major strengths of pressure groups - in fact the levelling factor in their confrontation with powerful companies - is their ability to exploit the instruments of the telecommunication revolution. Their agile use of global tools such as the Internet reduces the advantage that corporate budgets provided."

Disseminating certain information outside "regular" channels has shown to be a strong lever. Klein quotes Simon May, Shell's Internet Manager:

"There has been a shift in the balance of power, activists are no longer entirely dependent on the existing media. Shell learned it the hard way with the Brent Spar, when a lot of information was disseminated outside the regular channels."

Information circulated online can have a strong impact on companies and their reputations. Aaker and Joachimsthaler (2000) note that "customers with a bad experience can reach thousands of people instantly at no cost." Companies clearly need to be aware of potentially threatening information that is circulated online. There are even claims by PR people that companies who fail to monitor Internet traffic may be headed for a public relations disaster (Ulfelder 1997). Various reported incidents illustrate the threat potential, for example the designer Tommy Hilfiger was the victim of a threatening urban legend. The legend goes that Hilfiger appeared on the Oprah Winfrey Show, made racist comments about several groups and was then tossed off the set by Winfrey. In fact, Hilfiger has never appeared on or taped an episode of Winfrey's show. However, the legend spread so rapidly and generated so much controversy among customers and potential customers that the company was forced to respond on the Internet. To fully 
understand the threat potential it is important to know that the brand "Tommy Hilfiger" draws some of its strengths from its popularity among ghetto kids and hip-hop fans (Klein 2000).

\section{LIMITATIONS OF ICT}

In order to be able to react to threatening information disseminated online, companies need to know what is circulating on the web. This could be interpreted as a third role of ICT - helping re-establish the traditional information relationship between corporations and consumers. Companies, notably eWatch (www.ewatch.com), CyberAlert (www.cyberalert.com) and IntelliSeek (www.intelliseek.com), offer specific tools that help companies search the Web and other information sources to find out what is being said about a company and its products. However, the strengths and weaknesses of commercially available Internet surveillance tools are largely unknown. Furthermore, even the technically most advanced search technology is subject to a variety of limitations (Lueg 2001).

First of all, only a limited number of electronic communication channels are publicly accessible. Among the open channels are Usenet newsgroups, parts of the World Wide Web and public mailing-lists. In contrast, e-mail is mostly private, many mailing-lists are for closed user groups and many web servers have password-protected areas. Secondly, even in the case of the publicly accessible web, it is simply impossible to monitor all traffic for resource reasons (bandwidth, storage capacity, processing power). In 1998, researchers found that coverage of the web by search engines was severely limited: no single search engine indexed more than about one-third of the 'indexable web'. The web has expanded enormously since then which means that coverage can be expected to be much worse. Many web servers generate web pages on the fly, which means that scanning these pages implies scanning the databases the pages are generated from. Thirdly, even state-ofthe-art search and retrieval technology is only good at searching for known terms. When people use special nick-names when talking about products or companies it is hard for search technology to find out what people are talking about. Simple examples observed in online discussions are "Wuergerking" (a German language pun) instead of "Burgerking" or "McDoof" (another language pun) instead of "McDonald's". Fourthly, it is difficult for automatic search tools to find out what people actually do when they are talking about things. Removing discussions from their particular social contexts ('de-situating') may result in inaccurate interpretations.

Finally, even if search technology detects mention of corporations or brands, this information is already disseminated. Web sites can be closed but 
this process takes some time and often the pages are already scanned by search engines, such as Google (http://www.google.com), that store images of indexed pages. Email cannot be 'removed' once disseminated over mailing lists and stored in personal mailboxes. Usenet articles can be deleted on some news servers but many servers do not honour cancelling requests. Private archives are mostly inaccessible.

Of course, ICT is limited on the side of counterattacks as well. In order to be effective, counterattacks need to reach a sufficient number of receptive minds. Disseminating information has become cheap but targeting information and creating a "critical mass" may still be difficult.

\section{FUTURE IMPACT OF ICT}

As Spencer (1997) observes, the world has changed and there is no going back to the traditional situation where large-scale information flow was easy to control as it relied on scarce, expensive machines. Kania (2001) argues that users go online to find information and that the rich amount of information available online has enabled "super-empowered users". While this clearly is an opportunity for corporations to offer brand information, customers can be expected to access independent information channels as well. It is widely recognised that the Internet has enabled radically new ways for customers to share information but so far it seems that assessment of these alternate communication channels in the marketing literature is based on experiences with more traditional media. We found surprisingly little discussion of the threat potential of ICT in the context of branding. The fact that not only branding and marketing organisations but also counterattack activists make use of human cognitive characteristics by creating and manipulating memes, indicates that corporate influence is limited as long as uncontrollable communication channels exist.

Considering that the power of memes is known, the relationship of ICT, information dissemination and human memory has received surprisingly little attention. It is well known that advertising may create false product beliefs. The manufacturer of a mouth-wash, for example, created the impression that the mouth-wash would be an effective preventative against cold and had been censured by the Federal Trade Commission (FTC) for misleading consumers. What is less known is that human memory may be influenced. It is possible to use information to make people remember past experiences differently or things they never experienced. Braun and Loftus (1998) have shown that although graphical information seems to have a stronger impact, even textual information can be used to influence memories. This impact is important as experiments suggest that consumers 
use their memories of products when browsing supermarket shelves. Colour of products seems to be extremely important. Under certain circumstances textual information can be used to change memory of colour. It would be interesting to look at potential impacts of these and similar effects in the context of ICT when corporations use ICT to disseminate brand information and when activists use ICT to create counterattack memes.

Based on the information presented in this paper we expect that the virtually unrestricted (and hardly controllable) information flow in the Internet will support what The Economist (2001) predicts:

"Brands of the future will have to stand not only for product quality and a desirable image. They will also have to signal something wholesome about the company behind the brand".

\section{REFERENCES}

Aaker, D. and Joachimsthaler, E. (2000) Brand leadership. The Free Press. New York, NY, USA.

Braun, K. and Loftus, E. (1998) Advertising's misinformation effect. Applied Cognitive Psychology,12, pp. 569-591

Downes, S. (1999) Hacking memes. First Monday 4(10).

The Economist (2001) Special Report Brands: September 8th, pp. 9, 26-28.

Eriksson, E. A. (1999) Information Warfare: Hype or Reality? The Nonproliferation Review, Spring/Summer. pp. 57-64.

Kania, D. (2001) BRANDING.COM. NTC Business Books (In conjunction with the American Marketing Association). Lincolnwood, IL, USA.

Klein, N. (2000) No logo. Flamingo. An Imprint of HarperCollins Publishers, London, UK. Citations from the edition published in Australia in 2001.

Lueg, C. (2001) A distributed cognition approach to integrate security management and business processes. In Proceedings of the 2nd International Conference on "Working with e-Business", Perth, WA, Australia.

MediaGuardian (2001). Jonah Peretti and Nike.

[http://www.mediaguardian.co.uk/news/story/0,7541,440022,00.html]

Peretti, J. (2001) Culture jamming, memes, social networks, and the emerging media ecology: the "Nike sweatshop email" as an object-to-think-with. [http://www.media.mit.edu/ peretti/nike/]

Porak, V., Geissler, U. and Einwiller, S. (2000) Corporate media: an approach for corporate community management. In Proceedings of the 8th European Conference on Information Systems.

Spencer, H. (1997) Age of uncontrolled information flow. The Information Society 13, pp. 163-170. Taylor and Francis.

Ulfelder, S. (1997) Lies, damn lies and the Internet. Computerworld. 